\title{
Al-Sadu Weaving: Significance and Circulation in the Arabian Gulf
}

\author{
Rana Al-Ogayyel and Ceyda Oskay
}

1

Introduction

Traditional Bedouin al-Sadu weavings are nomadic, narrow-loom weavings that are warp-faced, ${ }^{1}$ a technique used mostly by women to weave tent dividers, cushions, and pillows inside the tent. The cloth is woven to become tight and strong to prevent the rain, wind, and sand from entering the tent. The most decorative parts of the nomadic tents are the tent dividers, which are often woven with a pattern in the center called shajarah, while the decoration on the outside of the tent is simpler and mostly striped. The warp-faced al-Sadu weavings are occasionally combined with the ragaoum technique, in which additional threads are woven horizontally across the weft, making the fabric look slightly raised above the regular weaving and creating a different texture (fig. 8.1).

Al-Sadu weavings are widespread across Middle Eastern countries and their motifs differ from region to region. They can be categorized by date, tribe, weaver, or region, and as such they can help in tracing regional and personal trends, as well as, possibly, historical and tribal events. Although over the course of time al-Sadu weavings have experienced significant alterations under the influence of urban development, synthetic dyes, mass production, commercialization, and expanding urbanization, they are still important elements in the construction of a local, tribal, or personal identity for the women weavers.

This chapter builds upon existing literature on al-Sadu weaving and the authors' direct knowledge

1 The warp and the weft are vertical and horizontal threads in a weaving, respectively. In different types of weavings, the pattern may appear on the weft or on the warp, hence the terms "warp-faced" or "weft-faced." of being a Saudi or living in Kuwait for extended periods of time. ${ }^{2}$ As al-Sadu tradition is transmitted orally, first-hand information was essential for this study. It involved direct observation, interviews, and focus group discussions with contemporary weavers from Kuwait and Saudi Arabia. To find the weavers, the authors contacted Al Sadu Weaving Cooperative Society in Kuwait City, Kuwait (also known as Sadu House), and the Ministry of Culture in Riyadh, Saudi Arabia. Because most of the symbols in the al-Sadu weavings or the stories behind them have been forgotten or intentionally kept secret, the authors have also engaged in archival work in order to unveil and catalogue some of their meanings. ${ }^{3}$

This chapter attempts to situate al-Sadu weavings in relation to cultural and historical knowledge, thus enriching its technical aspect with a

2 Rana Al-Ogayyel is a Saudi fine artist and Lecturer in the College of Art and Design at Princess Nourah Bint Abdulrahman University, K.S.A. She has observed the craft and studied the changes in al-Sadu weavings, which are an important part of her culture, throughout time. Ceyda Oskay is a an artist who consulted for The Sadu House in Kuwait, where she developed and ran the first Sadu Art and Design Initiative (SADI) program. She took weaving courses from Joy Hilden, Um Turqi, and, in recent years, Muteira AlMuassalim. Her observations are based on fieldwork carried out in Kuwait over a period of two years (2015-2016), previous fieldwork on tribalism in Kuwait (2007-2010), and having lived in Kuwait and Saudi Arabia for over thirty years.

3 An electronic archive of symbols and a physical archive of weavings are currently hosted at Sadu House in Kuwait City. Oskay initiated focus group discussions around some of these pieces with Kuwaiti weavers. She also consulted the Sadu House database of recorded symbols, al-Sadu collections in Kuwait, and the al-Sadu displays at the Safir Hotel, Failaka Island. 


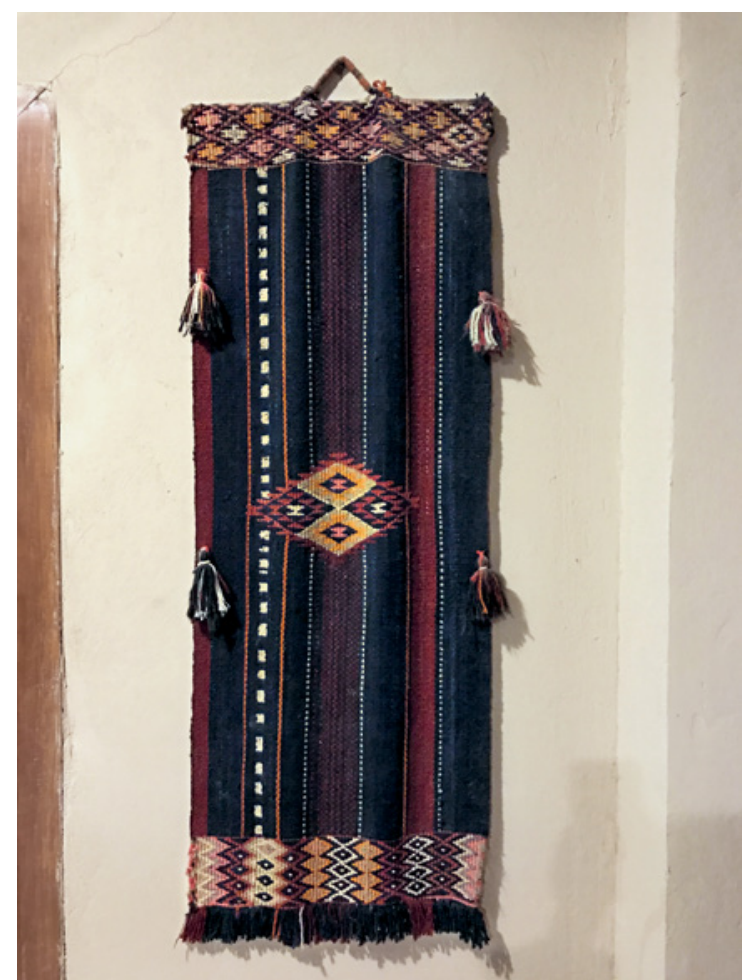

FIGURE 8.1 Al-Sadu weaving with ragaoum technique displayed at The Safir Hotel, Failaka Island (date unknown).

cultural and social understanding of this practice. ${ }^{4}$ Because the symbols in these weavings include astronomical and social elements, the authors concluded that, in the past, women may have been more involved in the socio-political structure of their communities than they are currently thought to be. While weaving, women were in a position of narrating or documenting stories whose meanings are lost to us now. This idea was emphasized by the weaver Umm Mohammad in her interview with Keireine Canavan and Ali Alnajadah: while careful to note that she only spoke for herself, she pointed to the practice of using al-Sadu to pass messages between tribes. ${ }^{5}$ Therefore, this chapter aims to

4 See also Ceyda Oskay, "Tribalism, State-Formation and Citizenship in Kuwait” (Master's thesis, Middle East Technical University, 2010).

5 Keireine Canavan and Ali Alnajadah, "Material Symbols of Traditional Bedouin Al-Sadu Weavings of Kuwait," Textile: Cloth and Culture 11, no. 2 (2013): 152-65. shed new light on women's social role in the Arabian Middle East and challenges narratives, myths, and stereotypes of the place not through external descriptions but through the voices of the female weavers who wove about the society or community they lived in. Because the nomadic tribes of the Gulf area did not keep many written records, textiles are also important historical and trans-cultural documents, with the scribes in this case being the women of the tribes. As such, al-Sadu is significant not only for textile studies but also for material, regional, and gender studies at large.

\section{2}

\section{Al-Sadu Weaving from Past to Present}

Traditional al-Sadu is a nomadic weaving used for tent and its furnishings that is mainly done by women. It is still carried out today by weavers in Saudi Arabia, Kuwait, the U.A.E., Bahrain, Qatar, and other Gulf countries, despite the radical social and economic changes they experienced after the oil boom. ${ }^{6}$ As many Bedouin tribes traveled to Syria, Jordan, and Iraq, al-Sadu weaving has extended to those areas as well, although the need for this practice has significantly decreased in recent times. ${ }^{7}$

As Homi K. Bhabha suggests in his seminal book, The Location of Culture, repeating the past by re-presenting it in different forms is an attempt to establish authority over unfamiliar situations. ${ }^{8}$ In other words, we try to gain knowledge about the things of the past to establish our position in relation to them. This gives rise to questions about time: as a thing changes its function over time, it reflects the time in which it was made. While alSadu as a material object is fixed, it is also rooted

6 As of 2011, al-Sadu is on the UNESCO's List of Intangible Cultural Heritage in Need of Urgent Safeguarding in the U.A.E. Cf. UNEsco Decision of the Intergovernmental Committee: 6.Сом 8.21.

7 For details, see Joy Totah Hilden, Bedouin Weaving of Saudi Arabia and Its Neighbours (London: Arabian Publishing, 2010); Dawn Chatty, From Camel to Truck: The Bedouin in the Modern World (New York: Vantage Press, 1986).

8 Homi K. Bhabha, The Location of Culture (London: Routledge, 1994), $5^{2}$. 
in nostalgia and history, so our way of reading it changes depending on how much we know about the meanings of its symbols and the conditions in which it was made and used. Moreover, by being reproduced in new materials or designs, al-Sadu allows for a reclaiming of heritage and personal expression. As the Gulf countries' economies and environments have developed rapidly in recent past due to the discovery of oil, they have also displayed a strong impulse toward preserving their local culture, which explains their renewed interest in al-Sadu weaving. As a result, its design has been adapted onto new materials, re-worked in new colors and patterns (mainly in Saudi Arabia and Kuwait), re-interpreted in fine art (in Kuwait, the U.A.E., and Saudi Arabia), or preserved in traditional weavings used for decoration, national competitions, and personal expression rather than for practical purposes (Kuwait).

Al-Sadu must have come into being primarily as a domestic necessity, before any patterns and motifs emerged. However, the patterns and motifs used are a form of self-expression, a recording of the local visual culture, and a way of inter-tribal communication. ${ }^{9}$ The symbols add a new dimension to the weavings, allowing us to look back and gain insight into the local cultures in which they were produced. As important material culture researcher, author, and patron of Al Sadu Society in Kuwait, Sheikha Altaf Al-Sabah, notes, al-Sadu weaving illustrates the nomadic Bedouin understanding of an eternal space. Unlike the designs in the frame of a floor carpet on a frame loom, which symbolize a window or a door to the world, and thus a settled relationship with home, landscape, and space, al-Sadu designs are suggestive of openness. ${ }^{10}$ In other words, the concept of a measured

For details, see Joy Totah Hilden, "Bedouin Textiles of Saudi Arabia," in Oriental Carpet and Textile Studies, ed. Murray L. Eiland, R. Pinner, and W. Denny (Berkeley: International Conference on Oriental Carpets, 1993), 4:1-18, and, by the same author, Bedouin Weaving of Saudi Arabia and Its Neighbours.

10 Sheikha Altaf Al-Sabah, interviewed by Ceyda Oskay, Kuwait City, December 2015.

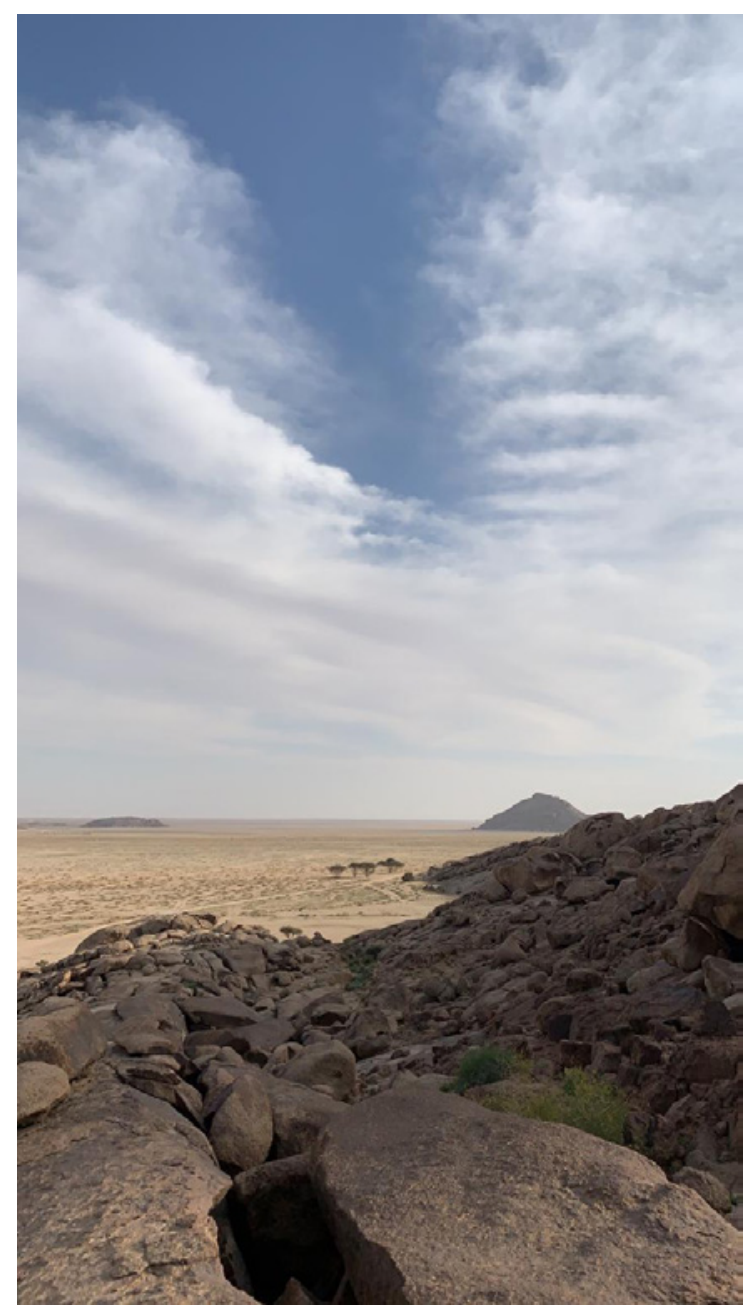

FIGURE 8.2 Desert land, Al-Qassim region, 2019.

space did not exist for the Bedouins traversing a vast, open desert, as it was not necessary for their understanding of the world. As Sheikha Altaf AlSabah explains, space to the nomad was without borders or boundaries. Therefore, the Bedouins were presented with a great challenge when they switched from a nomadic way of life to a life determined by a boundary, that is, a settled and permanent space. ${ }^{11}$ Their lifestyle shifted from inhabiting an open space, without a fixed architecture, to living in a more organized and strictly delineated space, with architectural landmarks and town planning (figs. 8.2 and 8.3).

11 Some tribes would migrate back and forth to specific territories according to seasons, so they were semi-settled. 


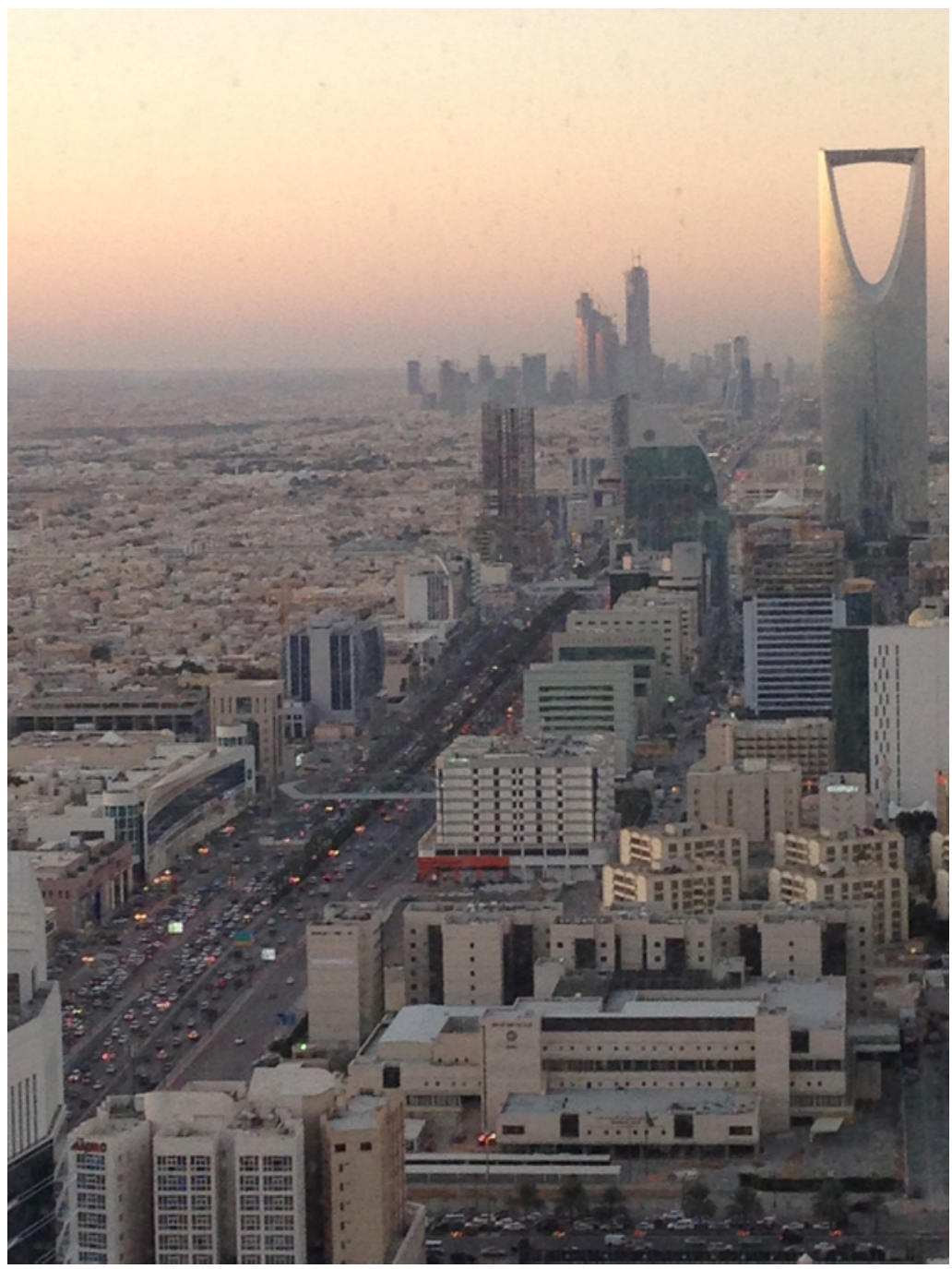

FIGURE 8.3

City land, Riyadh, 2019.
For Bedouins, therefore, the tent itself is not an object in the same sense as other architectural elements, such as doors or bricks, are because it is both an object and a space. This space is occupied according to the demands of the land, weather, and relationship with guests. For example, the separation created by a tent divider affects people's behavior and the way they move: the materiality of the space impacts the fluidity of their movement and the rhythm of their navigation through different parts of the home. When male and female guests arrive, the space of the tent is used in a segregated way; however, if the inhabitants are close family members, the leisure and sleeping spaces are not separated anymore. In The Arab of the Desert, H.R.P. Dickson describes the general architecture of a three-pole tent, mentioning nattu, or mattarih (both names for al-Sadu weaving ground loom), and explains the structure of a tent divider, sketching its first, second, third, and fourth strips (i.e., saif, al-ghadir, al-ba'ij, and almuta'ba). ${ }^{12}$ These details highlight the importance

\footnotetext{
12 H.R.P. Dickson, The Arab of the Desert: A Glimpse into Badawin Life in Kuwait and Sau'di Arabia (London: George Allen \& Unwin, 1949), 66-67 and 56, respectively. Different regions have different names for the ground loom, such as naul, nattu, sadu, or matraha; the tent divider is called qati or ibjad.
} 
that al-Sadu weavings had in organizing the inhabited space of the nomadic populations.

In the past, these woven soft homes sheltered both animals and people during their seasonal migrations. As animal herders, the Bedouins used to migrate to the desert during the rainy winter season and move back to the cultivated land in the dry summer months. Today, after the movement of most nomadic people to cities or villages, these portable houses and the practice of moving from one place to another have been replaced with modern living conditions. The contrast between the Bedouin home and the house reflects to some extent the contrast between the desert and the city: in the desert, there were no large groups of people living together, like in a city. The closest thing to a city was a soft quarter of moving homes inhabited by people belonging to the same tribe. As a result, belonging to a tribe constructed one's identity more than the space did. A tribe's identity was depicted as a sign, known as wasm, which was sometimes included in the shajarah section of alSadu textiles (i.e., a narrow-patterned stripe that runs through the tent divider). Customarily, a tribe's wasm was composed of a combination of simple, quasi-linguistic elements or abstract symbols, laying on a semi-symbolic plane.

According to Jean Baudrillard, two criteria must be met by an object to be identified as art: it must have a signature, and it must be part of an oeuvre. ${ }^{13}$ In the past, the wasm was such a signature: it helped Bedouins identify the tribal and regional origins of the Arabian weavings, as well as the animals branded with the tribe's mark. Today, al-Sadu has started to be signed by weavers by using their personal signs rather than the tribal signature wasm. Moreover, the weavers have their own body of work which displays their individual style. This makes the difference between "craft" and "fine art" objects difficult to define in al-Sadu work. For

13 Jean Baudrillard, For a Critique of the Political Economy of the Sign, trans. Charles Levin (St. Louis, MO: Telos Press, 1981), 102.

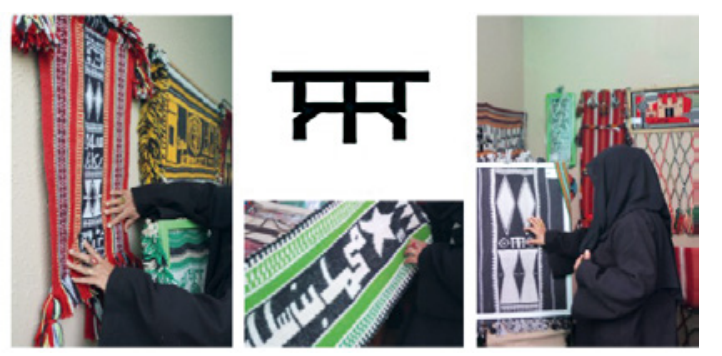

FIGURE 8.4A-D Refah Al Raheel's individual sign, 2016.

example, in contemporary times, weaver Refah $\mathrm{Al}$ Raheel has designed her sign as a symbol composed of the first letter of her first name and the first letter of her surname, "R.R." (fig. 8.4a-d). ${ }^{14}$ This is not a wasm anymore but a logo, similar to the ones in Western cultures: it identifies a brand or shows the identity of the weaver rather than that of the tribe.

\section{$3 \quad$ Al-Sadu as Material Culture}

Material culture considers not only the physical nature of an object but also its cultural associations. This implies a revaluation of the material culture of Saudi Arabia and other Gulf countries because, in their case, we need to compare nature and culture and regard them as valuable resources that need to be preserved and presented to a wider audience. On the one hand, their material craft culture is in danger of disappearing because of the fast and radical changes in the economy of these countries; on the other hand, this economic shift has created the need for a consolidation of these countries' identities in the contemporary, increasingly globalized world. This double process has triggered a series of festivals and other opportunities for artists to practice their craft and promote their work both inside and outside the Arabian Peninsula, as well as a strong move toward

14 Refah Al Raheel, interviewed by Rana Al Ogayyel, Riyadh, January 2017. 
museum building and other forms of cultural preservation. ${ }^{15}$

Al-Sadu is only one of the many early cultural objects that emerged from the Arabian desert. Because al-Sadu was so vital to the life in the desert, it has changed less than other objects and it lends itself closer to an authentic Arabic thing. Moreover, al-Sadu has never become mass-produced as a commodity from "Arabia." In other words, it was not commercialized early on in the same way coffee pots, trinkets, and Anatolian or Persian carpets were. As most of those carpets were made for interiors of settled shelters, they could be adopted into a European home easily, ${ }^{16}$ whereas al-Sadu did not fit well in non-tent homes or structures made of hard material, such as brick, concrete, or mud walls. Therefore, its history as a commodity, an object, or a thing was not extensively written, ${ }^{17}$ unlike that of the coffee pots, kilims, and other weavings. However, it is this very quality that has made it less prone to be transformed into some thing else.

The material culture of the Arabian Gulf is especially significant because it belongs to a society that has greatly relied on and valued the trade of objects throughout its history. As it was a mostly nomadic culture, ${ }^{18}$ its population used to keep

15 Examples include architectural decorations, calendar spreads, and company promotional objects that display traditional al-Sadu patterns. For additional examples, see Keireine Canavan, "Applications of Textile Products," in Textiles and Fashion: Materials, Design and Technology, ed. Rose Sinclair (Amsterdam: Woodhead Publishing, 2015), 541.

See, for instance, the many Renaissance paintings that show such carpets. Cf. Donald King and David Sylvester, eds., The Eastern Carpet in the Western World, From the 15th to the 17th century (London: Arts Council of Great Britain, 1983).

17 Interestingly, al-Sadu is hardly mentioned in early Arabian travel writing. It appears, though, in illustrations by H.R.P. Dickson, albeit their function there is strictly illustrative.

18 Hadhar is the word used to refer to the settled populations or tribes of the Arabian Gulf (including Iraq and Iran as many Hadhars are seen to be originating from only what could be carried on the backs of horses, donkeys, or camels. Thus, objects became even more significant as one had to carefully decide which object was worth carrying or not. To be easy to carry, al-Sadu was made of a flat weave woven in narrow strips hand-stitched together (figs 8.5a-b). An uncompleted weaving could be transported with ease as the loom was easy to dismantle and roll up (fig. 8.6). This nomadic tradition of the narrow loom and weaving sewn together in strips is also seen in eastern Turkey and Peru. However, in Turkey, it is a regular thin flat kilim weave, and not the thick warp-faced weave of the al-Sadu technique. Traditional weaving in Peru has also been noted to be similar to al-Sadu weaving. ${ }^{19}$

In this nomadic Bedouin setting, the home itself, that is, the tent itself, transforms from an object - weavable, foldable, packable, contained for transport - to a thing. ${ }^{20}$ The tent changes from wool to yarn to dyed yarn to a weaving in progress and then becomes a home when set up, a thing that "names ... a particular subject-object relation,"21 and an object again when packed up to

there), while Bedu or Bedouin is the word used to describe populations that were once nomadic. This distinction is still made today, even though a truly nomadic lifestyle is no longer widespread in this area.

19 Lucero Rodriguex, "Peruvian Textiles: The Origins, and Comparative Study with Traditional Textiles of Kuwait" (lecture, Al Sadu Society/Sadu House, Kuwait City, November 17, 2015). See also Elena Phipps, "Andean Textile Traditions: Material Knowledge and Culture, Part I," in PreColumbian Textile Conference VII, ed. Lena Bjerregaard and Ann Peters (Lincoln: Zea Book, 2017), 162-75; and Yanni Petsopoulos, Kilims, Flat-Woven Tapestry Rugs (New York: Rizzoli, 1979).

We use the term here in the sense given to it by Bill Brown, who aptly points out that things are more than objects of possession; for individuals belonging to a particular community, things are perceived as "inhabited" and "animated," while for others they are not. See Bill Brown, "Thing Theory," Critical Inquiry 28, no. 1 (2001): 9 .

Ibid., 4 . 


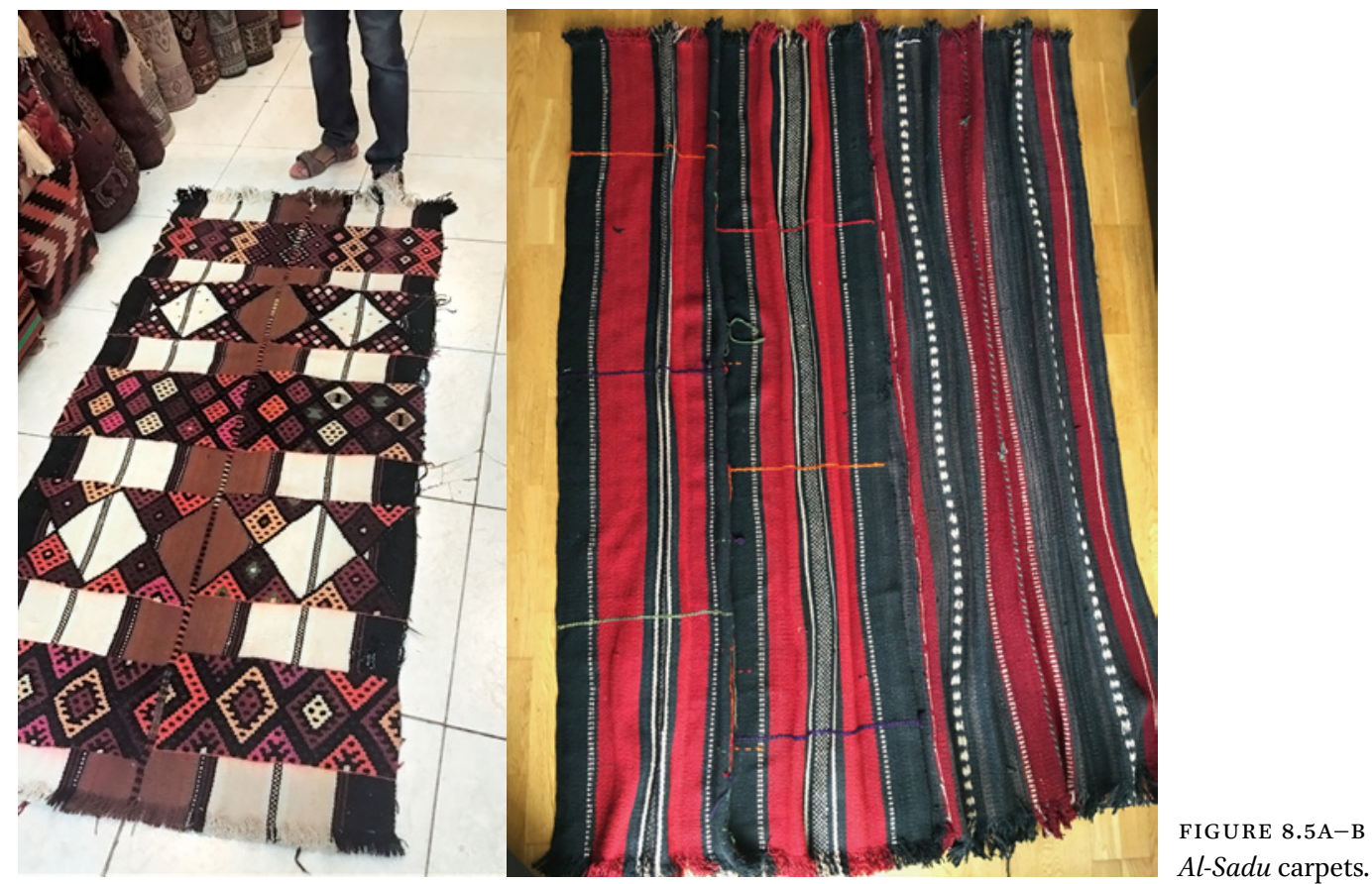

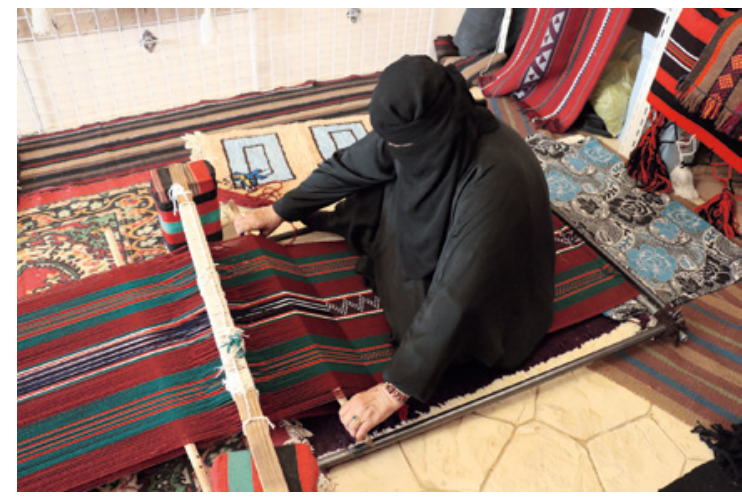

FIGURE 8.6 Al-Sadu ground loom.

be transported on a camel for nomadic journeys. The notion of "thing," therefore, is quite complex when examining a Bedouin tent. As Arjun Appadurai pointed out, the "things-in-motion" always illuminate their human and social context. ${ }^{22} \mathrm{~A}$ tent is an object the individuals have control over, then

22 Arjun Appaduari, "Introduction: Commodities and the Politics of Value," in The Social Life of Things: Commodities in Cultural Perspective, ed. Ajun Appadurai (Cambridge: Cambridge University Press, 1986), 5 . becomes external to them, a thing of complex symbolic value, and next becomes rolled up and object-like again. Moreover, the Bedouin tent can be reconstructed and moved to a different location, so it is recreated identically but slightly differently. ${ }^{23}$ Its feel is modulated by its new location in space.

The tools used in al-Sadu weaving are also important elements of the material culture of the area. Significantly, they come directly from animals. For example, a gazelle horn is used to divide the threads as the warp is picked up according to the patterns to be woven (figs. $8.7 \mathrm{a}-\mathrm{c}$ ). The tool originates from an animate being who is made into an inanimate object, unchanged except for being cut and cleaned. Al-Sadu wool is another object originating from a living source, an animal, as is the wool used in the weaving process itself. Thus, the craft itself is connected to nature in a profound, meaningful way.

23 Weavers interviewed by Rana Al-Ogayyel, Riyadh, January 2017. 


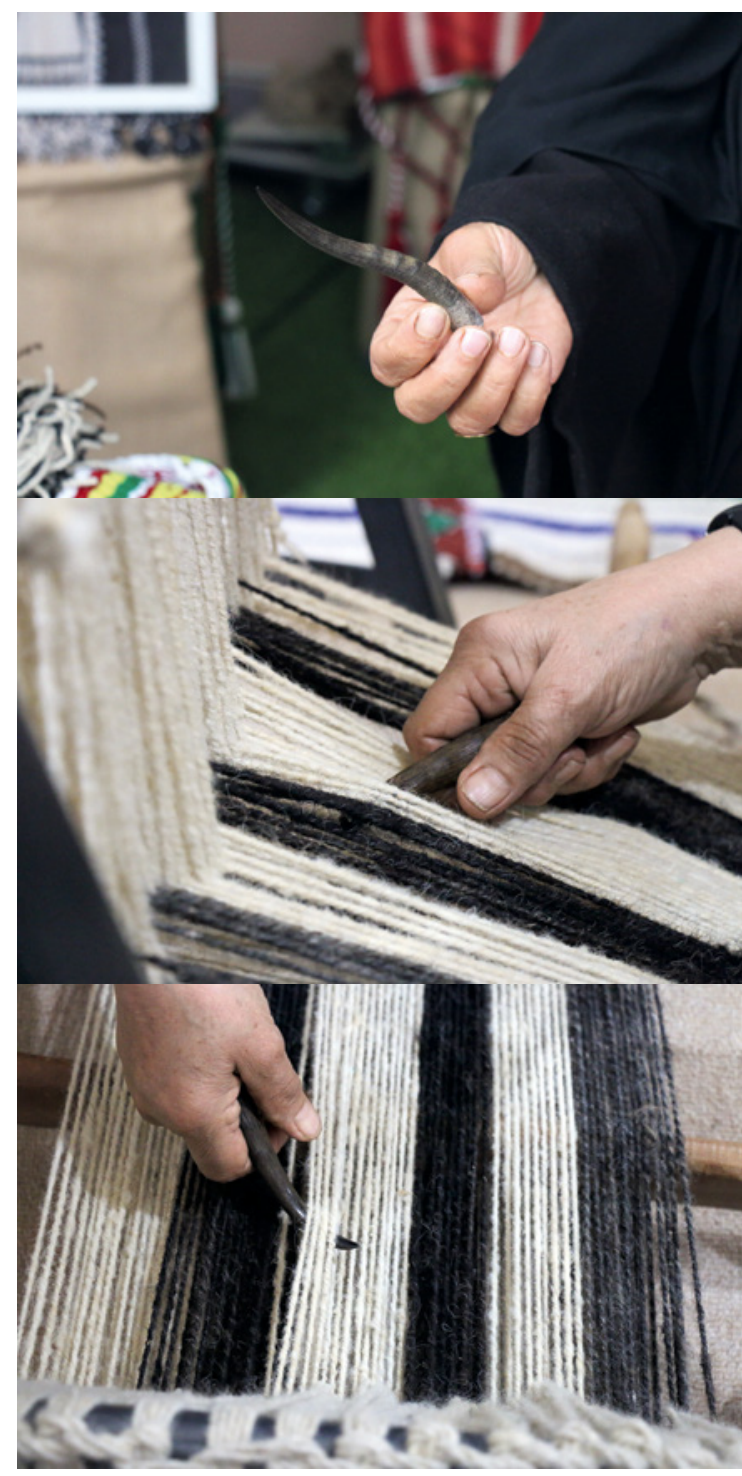

FIGURE 8.7A-C A gazelle horn used in al-Sadu weaving.

\section{$4 \quad$ Al-Sadu Symbols and Social Significance}

Perhaps the main reason for the uniqueness of al-Sadu weaving is that it was never mass-produced for export in the same way other carpets were. Although it was traded among tribes, due to the length of time it takes to produce a tent, and due to its particular function in the harsh climate of the desert, it was not replicable in other geographies. Al-Sadu weaving could not be commercialized in the same way that other

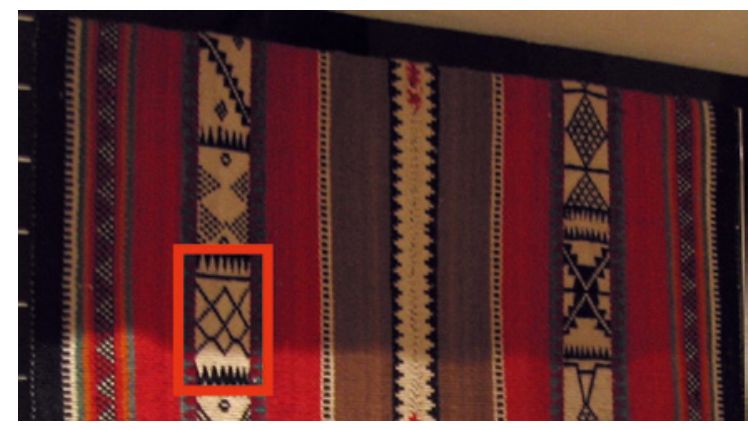

FIGURE 8.8 Symbol of stars in contemporary al-Sadu weaving by Leila Yaser.

objects—such as kilims, clothes, bags, blankets, and tablecloths-were in other parts of the world. Therefore, although the weaving practice and the symbols used may have changed, they did not change as much as in other textiles, so examining the symbols embedded in these weavings may yield a wealth of information about the life of local populations. In the absence of written records, al-Sadu weavings become, thus, records of memories embodied in a thing.

The natural environment of the nomadic tribe can be seen in al-Sadu designs, which contain symbols that reflect astronomical elements and the desert environment. ${ }^{24}$ Quite frequently, alSadu symbols indicate constellations and stars (fig. 8.8). ${ }^{25}$ In the vast sky of the pre-electric desert, the stars, the moon, and the sun had a great significance, being the main sources of orientation. It is important to note that, currently, the weavers in Kuwait explain these symbols simply as "stars,"

24 For more details on the symbols that appear in al-Sadu weavings, see also Altaf Salem Al-Ali Al-Sabah, Ibjad: Ornate Tent Dividers and Weavings of the Kuwait Desert (Kuwait: Al Sadu Society, 2006); Khawla Mohamed Abdel and Aziez Al Manai, Al Sadu (Doha: National Museum of Qatar, 2013); and Ali S. Alnajadah, "The Pictographic Codes in Al-Sadu Weavings of Kuwait," International Design Journal 8, no. 3 (2018): 63-74. In this latter study, Alnajadah tracks changes in the meanings of some al-Sadu symbols.

25 Khawlah M. Manna, Al-Sadu in Qatar: Traditional Technical Values and Techniques (Doha: Qatar Museums Authority, Qatar National Museum, 2013), 99-100. 
giving various symbols the same definition, ${ }^{26}$ which is consistent with the meanings identified in documentation from Qatar. ${ }^{27}$ However, in earlier weavings they may have been used to symbolize time, meteorological phenomena, the location of a particular event or, given the use of astronomy in the desert, wayfinding. ${ }^{28}$

Traditional symbols also included snakes, which are represented by a zig-zag pattern, or water, which is represented by concentric diamonds. The use of these symbols may be due to the fact that it is technically more difficult to weave curved shapes than straight ones, and it is easier to abstractify by repeating symbols. In contrast, Western cultures generally use more realistic, as well as anthropomorphic, images in crafted or handmade objects, although it is worth mentioning that al-Sadu weavings in Kuwait did contain images of human figures in the past (fig. 8.9). Human and animal imagery within weavings became taboo around the mid-1970s due to religious restrictions. $^{29}$ The weaving shown here is currently on Failaka Island; however, the deep blue color indicates that it may have been woven by the northern tribes. Most of these deep blue weavings use strong cotton thread for the white patterns and some can be more decorative, repetitive, motif-based, and flowery than the traditional red-and-orange $\mathrm{Ku}$ waiti weavings.

Al-Sadu weavings also contain images within the weaving, such as earrings, which are of particular significance for women. As Shelagh Weir explains, a Bedouin woman has her first jewelry

26 Muteira Al-Muassalim and Leila Yaser, interviewed by Ceyda Oskay, Al Sadu Society, Kuwait City, May 2016.

27 Manna, Al-Sadu in Qatar, 99-100.

28 Cf. Ceyda Oskay, "Sadu Nomadic Weaving in Kuwait: Looking at Possibilities of the Arabian al-Sadu Tent Divider Wall as Maps, Stories, and Self-Expression" (paper presented at the Fashioning Inclusivity Symposium, Textiles and Materials panel, London College of Fashion, London, June 2019). Special thanks to Deema Al Ghunaim for her useful insights into the possible meanings of the symbols.

29 Al-Sabah, Ibjad, 38.

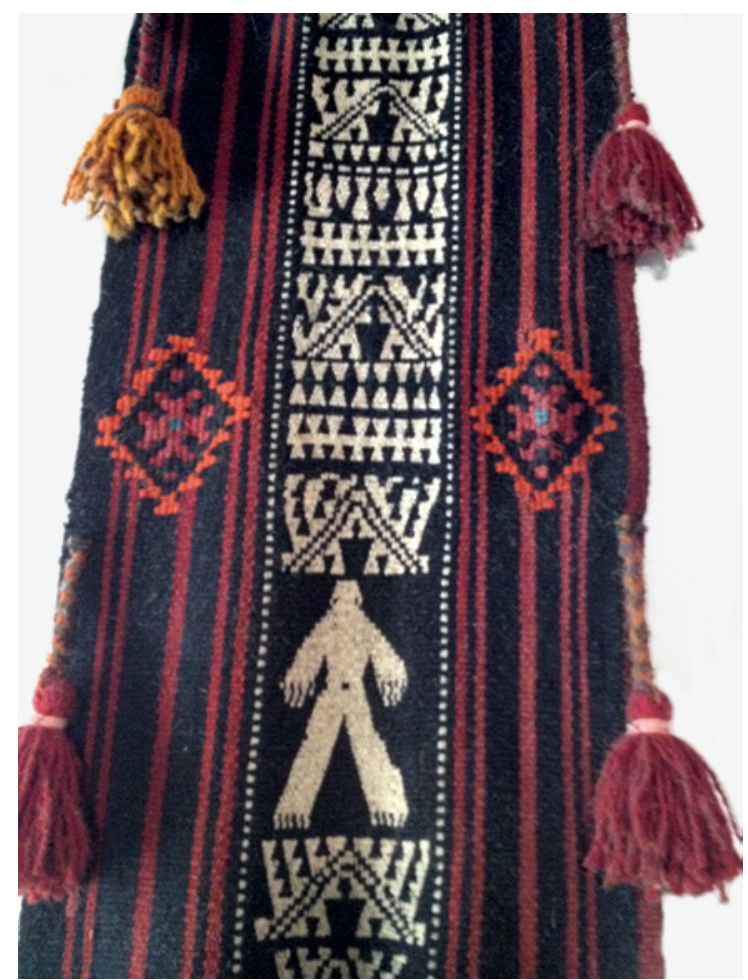

FIGURE 8.9 Al-Sadu weaving depicting a human figure on display at The Safir Hotel, Failaka Island, Kuwait (date unknown).

collection when she gets married, so such a collection is an indication of her marital status, similar to a wedding ring in other cultures. ${ }^{30}$ These pieces of jewelry were made by nuwar (gypsies) who used to travel the desert as silversmiths and made a living this way. ${ }^{31} \mathrm{Al}$-Sadu weavings reflect such practices and may contain a "record" of the jewelry's circulation. Indeed, when looking at these weavings, one can easily see symbols of earrings (fig. 8.10), which makes clear that socially-significant objects are embedded and archived in textiles. ${ }^{32}$

30 Shelagh Weir, The Bedouin: Exhibition Catalogue (London: British Museum Press, 1990), 71.

31 Ibid.

32 See Canavan and Alnajadah, "Material Symbols of Traditional Bedouin Al-Sadu Weavings of Kuwait." This idea also surfaced in Ceyda Oskay's interview with 


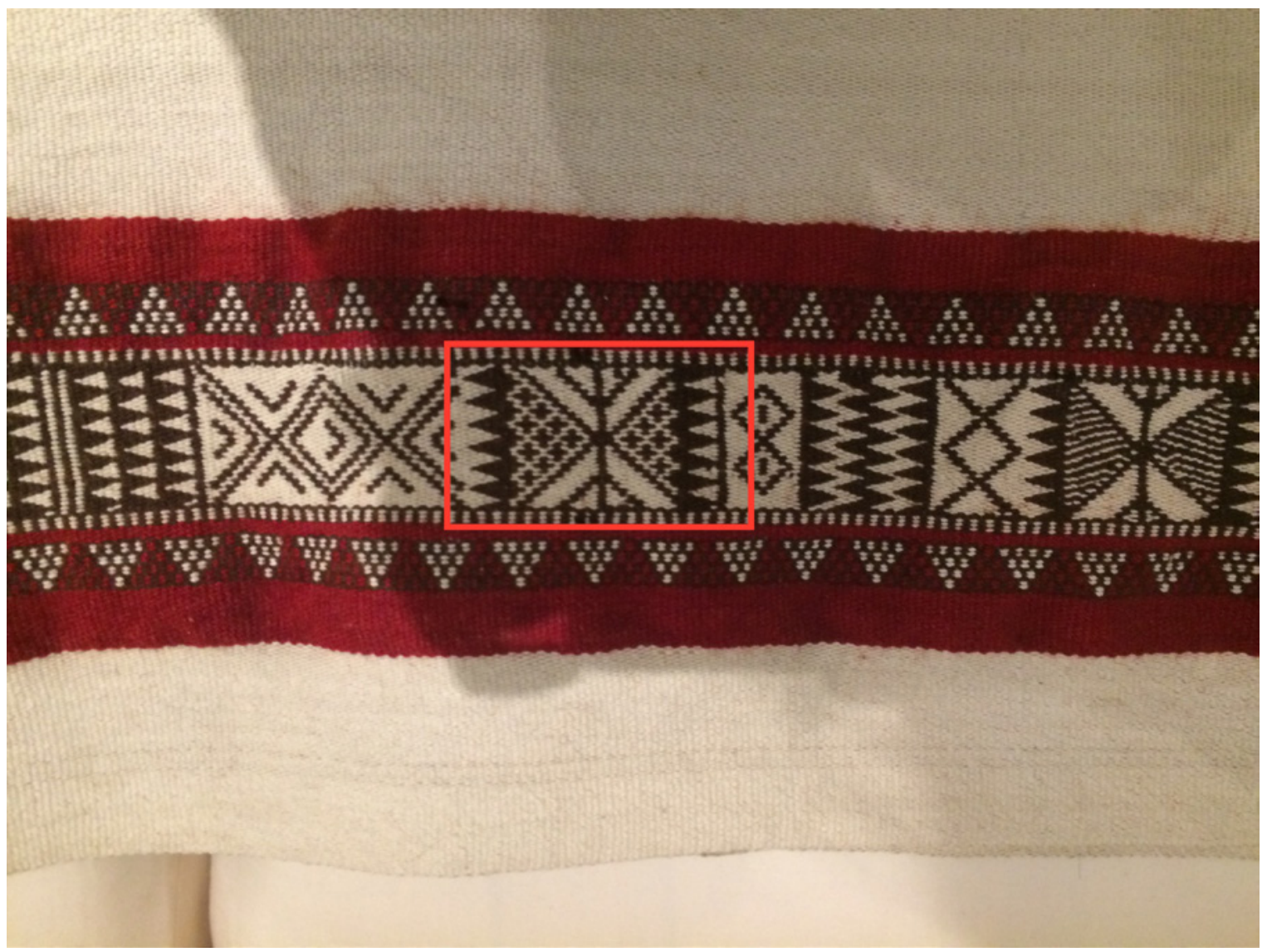

FIGURE 8.10 Symbols of earrings in contemporary al-Sadu weaving (weaver unknown).

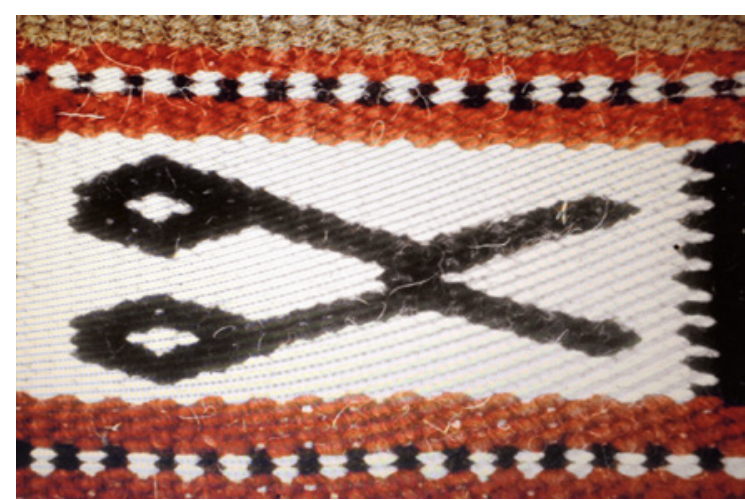

FIGURE 8.11

Symbol of scissors in al-Sadu weaving (date unknown).

weavers Muteira Al-Muassalim and Leila Yaser, Al Sadu Society, Kuwait City, May 2016.
Moreover, each weaver has her own motif and design related to the tribe. Joy Totah Hilden refers to this as a means of identification of the tribe and the weaver. As she explains, "a weaver can express herself here by writing names, dates and quotes from the Qurān. She can use traditional patterns and invent some of her own, using subject matter from everyday life."33 For example, weaver Refah Al Raheel mentioned during her interview that, "sometimes I weave a special type of al-Sadu souvenir for family occasions, such as weddings and births. And not just for my family; I also weave special pieces for the Prince's visits at national

33 Hilden, "Bedouin Textiles of Saudi Arabia," in Eiland, Pinner, and Denny, Oriental Carpet and Textile Studies, $4: 3$. 


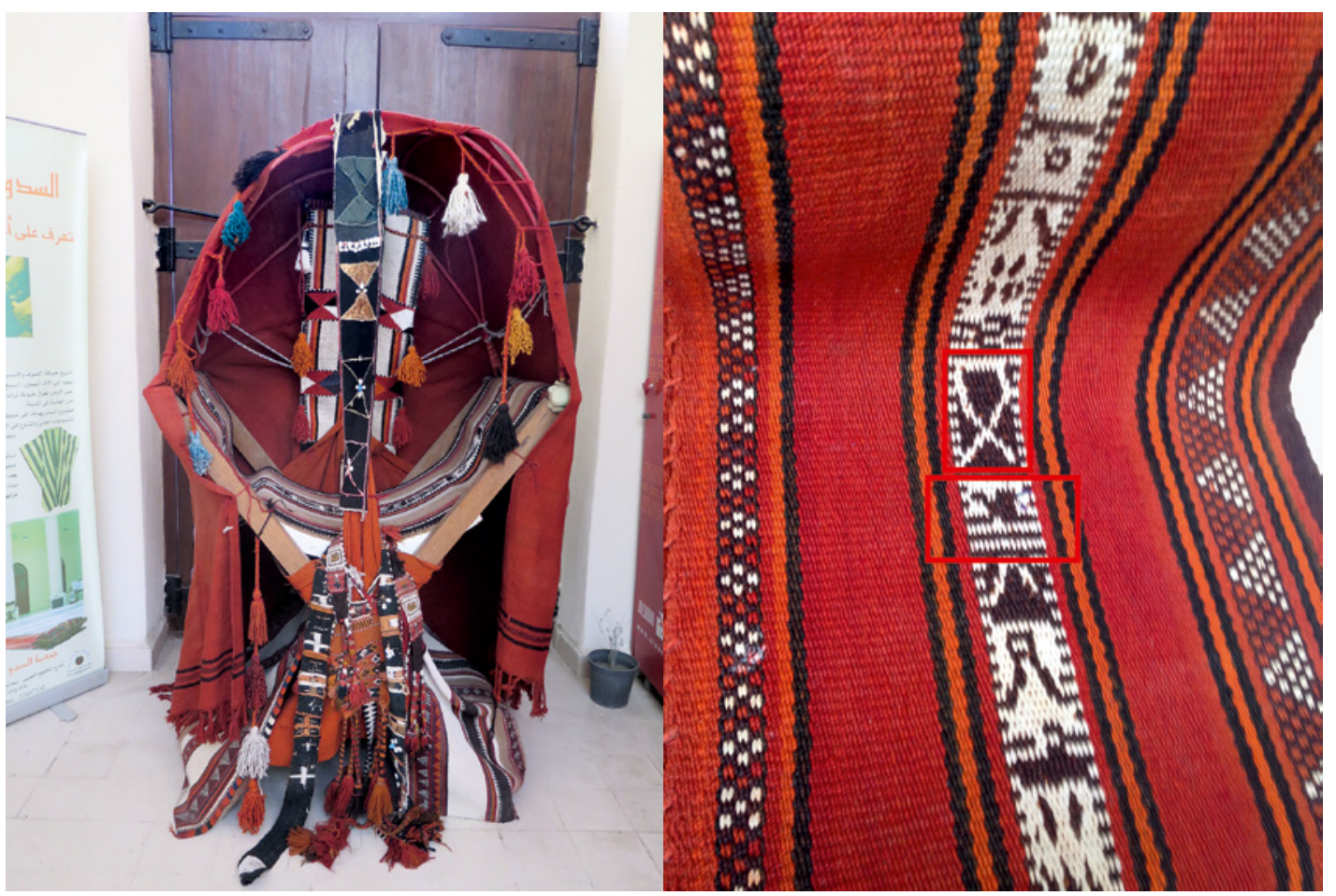

FIGURE 8.12A-B Al-Sadu weaving containing abstract representations of a kneeling camel with a carriage placed on top of it, used during wedding ceremonies (date unknown).

festivals." ${ }^{34}$ Thus, the weaving becomes a record of material culture as weavers frequently included images of new objects that the Bedouins encountered during travels or market exchanges, such as scissors (fig. 8.11).

Unfortunately, nowhere in the existing literature can one find an analysis of an entire weaving or of a group of symbols. In an attempt to explain the symbols used in a carpet displayed at $\mathrm{Al} \mathrm{Sadu} \mathrm{Society} \mathrm{in}$ Kuwait, for instance, weaver Muteira Al-Muassalim interprets them as describing the movements of a camel. ${ }^{35}$ She points out the different positions of the camel in the weaving and clarifies that it belongs

34 Refah Al Raheel, interviewed by Rana Al Ogayyel, Riyadh, 2017.

35

Muteira Al-Muassalim, interviewed by Ceyda Oskay, Al Sadu Society, Kuwait City, May 2016. Muteira is an experienced weaver who weaves her own contemporary pieces (mostly of blocks of color) in addition to more traditional ones, and who currently teaches weaving classes at $\mathrm{Al} \mathrm{Sadu} \mathrm{Society.}$ to the Ajman tribe because of the vivid reds and oranges that the tribe was known for (fig. 8.12a-b). ${ }^{36}$ She also notes that the tribe was o known for its strong regard of its camels. What is unknown, however, is whether these sequential positions are purely decorative or are indicative of a pathway in the desert, a ceremony, or have another meaning. Although we no longer know the extent of the storytelling in the carpets, we can assume that it played a major role in earlier weavings.

A major change to the Bedouin culture and, consequently, to $\mathrm{al}$-Sadu, was the rapid economic development of the Arabian Peninsula after the discovery of oil and state formation in the twentieth century. This caused the Bedouin traditions to decline as many locals became employed in the petroleum industry and the government. The nomadic lifestyle changed to a sedentary one, and the number of weavers dropped significantly. As a

36 For details, see Al Sadu Weaving Cooperative Society, 2009, https://www.alsadu.org.kw. 


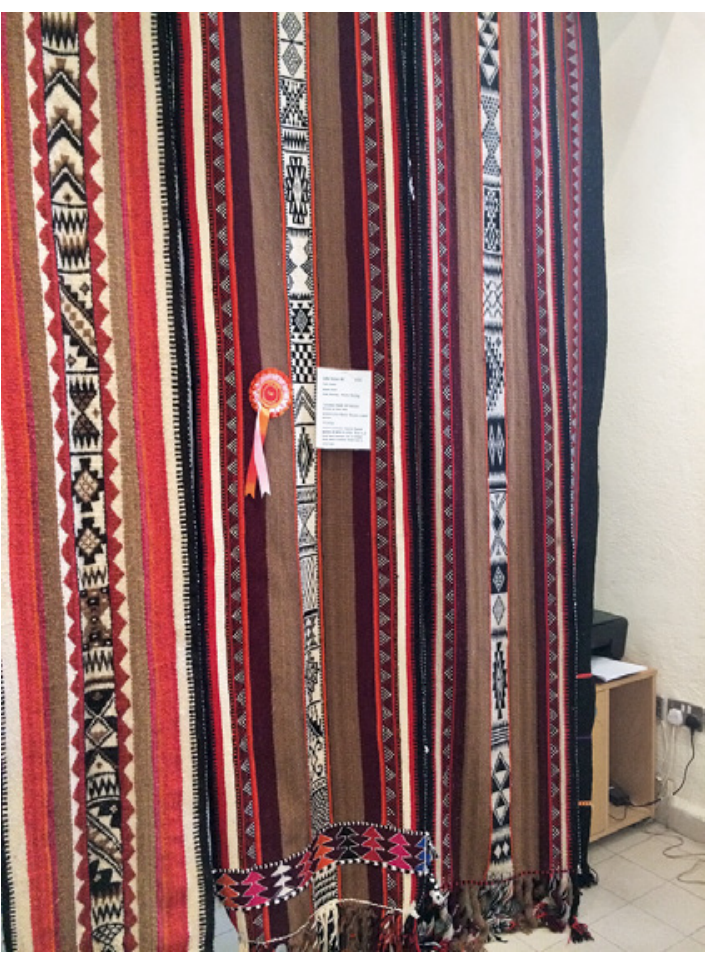

FIGURE 8.13

Laila Yaser's weaving showing the logo of the Kuwait television. This weaving was awarded the first place in the Al-Sadu Society's Weaving Competition, 2015-2016.

result, only few women weavers still have the knowledge, technical skills, and oral memories to handmake these artifacts. Following these economic developments and social changes, the symbolic value of al-Sadu has changed. For example, in Saudi Arabia the old motifs inspired by the surrounding natural environment have been gradually replaced with new ones, which reflect an urban environment. As a disappearing memory, al-Sadu has also changed its value from a functional to a cultural object. After losing its original function, it has gained new meanings, reflecting a changed lifestyle. For example, weaver Leila Yaser from Kuwait indicated during an interview that a symbol she was weaving was actually the logo of the Kuwait Television (KTV) ${ }^{37}$ (fig. 8.13). Other

37 Leila Yaser, interviewed by Ceyda Oskay, Al Sadu Society, Kuwait City, May 2016. Leila is a well-known weaver changes can be seen in the way weavers have developed their practice. Some use patterns that depict surrounding elements, such as figurations of buildings and the city, while others continue to consider al-Sadu as a symbolic language, although they often cannot remember its meanings due to the passing of time (figs. 8.14a-b).

Al-Sadu weaving contains motifs which, unlike motifs on carpets in other parts of the world, such as Turkey, for instance, which contain abstract symbols of abundance or fertility, ${ }^{38}$ function more like direct records of social history, current events, or spatial directions. Moreover, unlike other weavings, al-Sadu symbols are not as repetitive or only decorative. As these symbols are related to nature, seasons, stars, and tribes, this suggests that women-weavers may have been in an empowered position in society: their role of record keeping was not a passive but an active one. However, because the first writings that mention al-Sadu are travel narratives of the Middle East authored by foreign men who may have had limited access to the inside of the tents or less interest in the weavings, they do not include explanations of al-Sadu patterns that could shed light on women's empowered role in their communities. Only recently have researchers begun to explain the meanings of alSadu symbols and unveil the role played by female weavers in the Bedouin society. ${ }^{39}$

Given that nomadic tribes lived in close proximity, it would have been difficult for women weavers

who has won many medals in weaving competitions in Kuwait and who regularly displays woven pieces for sale at the Sadu House giftshop.

38 See, for instance, Dario Valcarenghi, Kilim: History and Symbols (Milan: Electa, 1994), and M. Nurdan Taşkıran, "Reading Motifs on Kilims: A Semiotic Approach to Symbolic Meaning," Kocaeli University, Istanbul (2006): 1-28.

39 As Canavan and Alnajadah argue in "Material Symbols of Traditional Bedouin Al-Sadu Weavings of Kuwait," "the women transmitted their own ideas of identity and culture over time" while also acting as preservers of "ideals and memory" (159). 


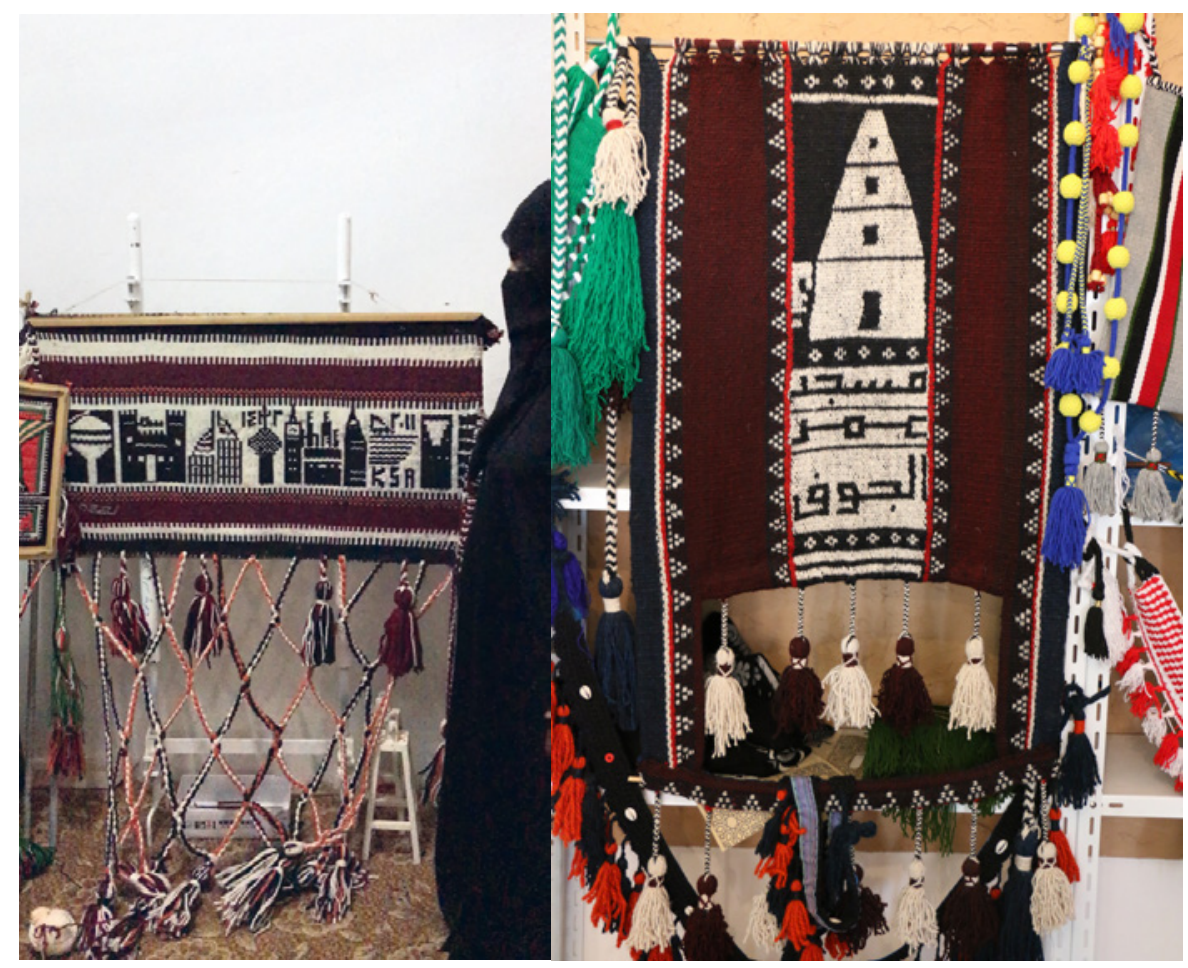

FIGURE 8.14A-B Contemporary weavings by Refah Al Raheel (a) and Wazifah Al Shamrii (b), showing modern al-Sadu patterns with figurations of buildings.

not to be aware of the social and political structures affecting the tribe. While it is assumed that a tribe would take the utmost care to segregate men from women, one wonders if this segregation was also extended to ideas and political participation. As Shirley Kay correctly points out, "Bedouin women have been less affected by such exclusions than town and village women. Segregation is not possible for a nomadic, tent-dwelling people as the women's work is necessary to the survival of the community. Women look after the flocks of goats and sheep and may spend long hours alone in the desert. Their safety is assured by a strict code of honor, but nothing prevents them from talking to a male friend." 40 These relationships are reflected by al-Sadu weavings in the color symbolism and patterns that describe tribe associations and traditionallabor interactions. From this perspective, $a l-S a d u$

$40 \quad$ Shirley Kay, The Bedouin (New York: Crane, Russak/David and Charles, 1978), 27. weavings play an important role in challenging assumptions of a strict hierarchy between men and women in the Arabian Gulf.

Al-Sadu weavings also function as records of economic and social exchanges in an indirect way. Plant dyes necessary for the craft were exchanged during the nomadic journey for a variety of things. These exchanges indicate that the tribes were engaged in networks of commercial relations with other tribes. Later, chemical dyes would be imported to Kuwait from India, ${ }^{41}$ so alSadu weavings also indicate political relations. It was not only the dyes that traveled but also currency and knowledge. For example, the Rupee was used as currency in Kuwait, many prominent Kuwaiti families went to India for education, and the British employed many Indian nationals to work in the Gulf. These multi-layered

41 See the display of dyestuff at Al Sadu Society, which includes boxes of chemical dyes from India. 
exchanges are indirectly embedded in al-Sadu weavings. As such, al-Sadu can be examined, to use Tim Dant's words, as "an object that mediates." 42 Such an object "carries communications between people-information, emotions, ideas, and impressions that could have been communicated by speech, gesture, touch, or expression if the people had been in contact with each other. The mediating object carries messages across space or time (or both) between people who are not co-present." 43

The colors used by the weaver encode important socio-cultural information as well. The standard colors (red, orange, beige, white, and black) may vary among tribes: Ajman tribes, for instance, have a predilection for orange and red. These colors also indicate the geographical expanse of a tribe's movement because they are based on plants growing in specific areas. Generally, bright red and bright or pinkish orange are extracted from madder; tan or yellowish orange come from onion skins; beige, black, and white are the original colors of the sheep's wool; and black comes from squid ink. Blue is extracted from indigo, and green may be a mixture of yellow and blue. ${ }^{44} \mathrm{In}-$ terestingly, the use of blue and green has varied throughout regions and time periods, indicating changes in fashion. ${ }^{45}$ These colors also varied

42 Tim Dant, Material Culture in the Social World: Values, Activities, Lifestyles (Buckingham: Open University Press, 1999), 153

43 Ibid

44 This information on natural dyes was gathered by Ceyda Oskay from interviews with carpet sellers in Turkey between 2012 and 2014, and weavers in Kuwait between November 2015 and June 2016. Although the Kuwaiti weavers indicated that they used natural dyes, during the discussions about dye recipes it became apparent that the percentage of alum mordant (dye fixer) they use was far lower than that used by the Turkish dyers. among geographies and tribes, as seen in the example of the weaving on Failaka Island. As Patricia Joyce Redding explains, the "preferred colors in Kuwait were the natural colors of sheep, camel, and goat hair," and dyed threads were "red and orange range, and occasionally with the addition of green and blue," while "the northern Arab tribes preferred dark blue and maroon." ${ }^{\prime 6}$ it is also possible that the northern tribes used blue more often due to the availability of certain dyes. This is, of course, a conclusion based on examining textiles only of the last century or so; the climates and plants of centuries ago, as well as past trade routes and personal and tribal preferences, would have had an influence on these choices. Thus, through colors and symbols, the weaver provides a variety of information about social roles, customs, landscape, and natural elements, playing a fundamental role in maintaining the identity and the social fabric of the tribe.

When looking at al-Sadu weavings through this lens, what differentiates them from other textiles is that the weaving itself contains a narrative component, like a scroll. Unfortunately, the secrecy that surrounded al-Sadu motifs has remained, and today the weavers are either reluctant to share these stories or have forgotten the stories behind the weavings. Also, the stories that used to be passed down orally from mothers to daughters have disappeared due to changes in culture and lifestyle. While older weavings contain a rich variety of shapes and symbols that form elaborated stories, the newer ones are more repetitive in motif and pattern and have fewer narrative elements, in line with the current commercialization of the craft as decoration and loss of the symbolic meanings of the patterns.

natural changes in taste, styles, and materials over time.

46 Patricia Joyce Redding, "Al Sadu Collection: Preserving Bedouin Weaving," in Museums and the Material World: Collecting the Arabian Peninsula, ed. Pamela ErskineLoftus (Edinburgh: MuseumsEtc, 2014), 347.

Al Sadu Society. However, in 2016, this was no lon ger a preferred color to weave with, which indicates 


\section{Al-Sadu as Transportable Home}

"Home" has a multiplicity of meanings. It can be the place where one grows up, one's family, the place where an individual receives an education and learns new skills, or simply a place where one feels safe. In her book, Art and the Home: Comfort, Alienation and the Everyday, Imogen Racz discusses the idea of home as a container of the self, as a physical memory of the individual and of his or her childhood. The author also outlines the concept of "threshold," which separates the internal from the external, the private from public spaces. In these spaces, different sets of rules apply. In her words, " $[\mathrm{t}]$ o cross the threshold from the public to the private world is one of the many transitions and rites that we unthinkingly perform every day. This physical movement creates a corresponding mental shift from being in a public area, where the rules and threats are beyond our control, to being in an area with which one is intimate." 47 In the Bedouins' portable home, such a threshold is embodied by al-Sadu.

For Bedouins, homemeans many differentplaces that are put together.It is home as awork in progress, which ultimately has less to do with a piece of soil and more with a space of the soul. The traditional Bedouin home (the tent, or bayt al-shaer, or "house of hair") is the protective home transported around by a nomadic family in its migrations. The reason why the bayt is called "the house of hair" is because the external panels and ceiling are made from goat hair that has been shorn, spun, dyed, and woven by the hands of al-Sadu weavers. It encompasses the ancestralidea of constructing one's home with one's hands; however, it is not the traditional home built by men's labor, but the soft home built by women's toil. The tent is the largest woven structure used by the Bedouins: it is completely surrounded by hand-made cloth — or al-Sadu fabric — which acts as a barrier that protects them against the hot, harsh sun in the summer and the cold or rain in the

47 Imogen Racz, Art and the Home: Comfort, Alienation and the Everyday (London: I.B. Tauris, 2015), 25. winter. This protection is extended to the livestock as well. The fabric walls of the bayt al-shaer can be lifted or draped, allowing the breeze to keep the interior cool in hot weather. The thick, heavy textile of the tent is the result of the process of shearing, spinning, dyeing, and weaving, which is all done by Bedouin women. Bedouin women are well known for manufacturing the "house of hair." They take part in the construction of the bayt right from its early stages, from shearing the animals and spinning the hair to weaving the threads to participating in erecting the bayt and taking it down again, in preparation for a move to a new place.

Claude Lévi-Strauss described the house as a social institution rather than just a space in which we live. A house is more than a physical entity: it is a construct of the mind, it is a home. ${ }^{48}$ While we build houses and make them suit our own purposes, we also use these houses and their image to identify ourselves as individuals and groups. Thus, the house becomes a home, which is a safe place that gives women the opportunity to work and create. In this environment, the women become providers for the family. The home is also the place where women first learn, practice, and develop their al-Sadu textile work. Although this practice has largely become a memory today because most of the Bedouin communities have moved to the city, where such artifacts are unnecessary, the nostalgia for that fading life continues to be alive in people's imagination and in contemporary visual culture.

The bayt's distinctive appearance is also important. It is different from other tents, such as the canvas tent, in that the outside of the bayt is mostly black (fig. 8.15). This is because the material comes from black goats, whose hair is very strong and almost waterproof. Some white sheep wool is used in the weave as well, so we may see some fine, white lines in the weaving too. Inside the tent, dividers are decorated with beautiful designs in

48 Claude Lévi-Strauss, Anthropology and Myth: Lectures, 1951-1982, trans. R. Willis (Oxford: Basil Blackwell, 1987), $15^{1-52 .}$ 


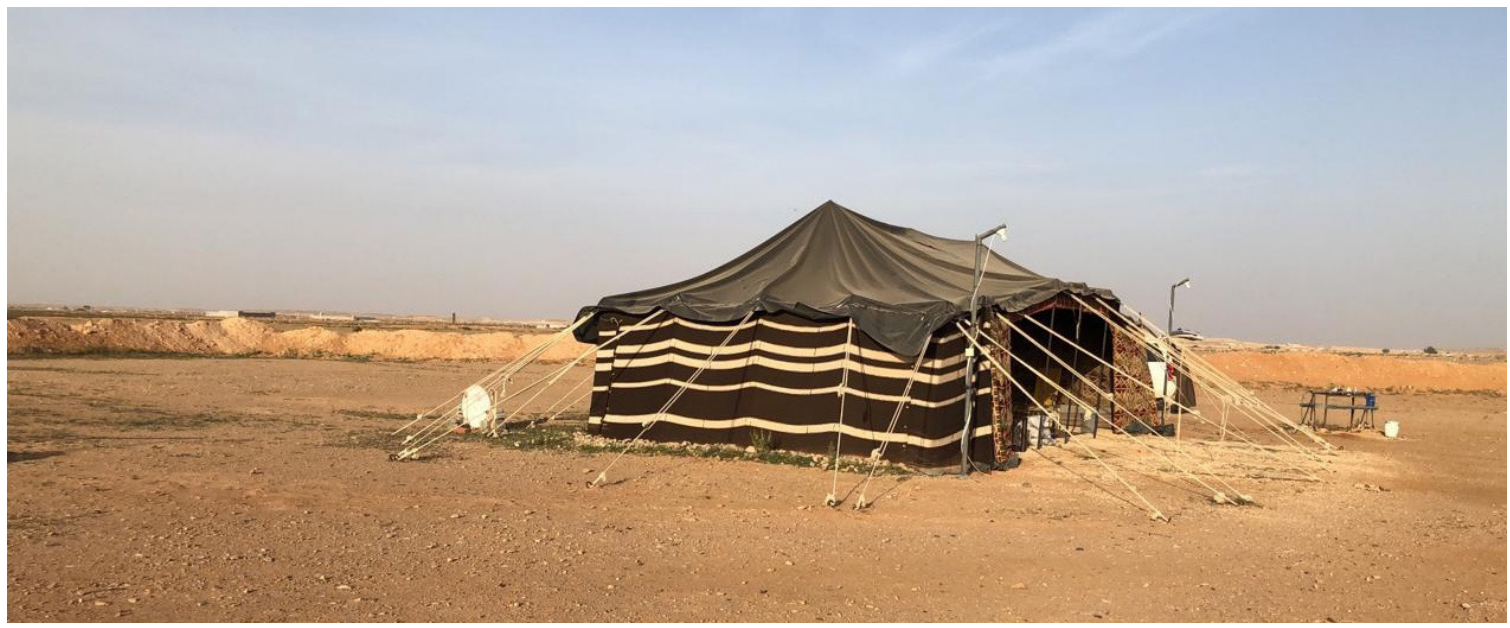

FIGURE 8.15 Typical black-and-white Bedouin tent.

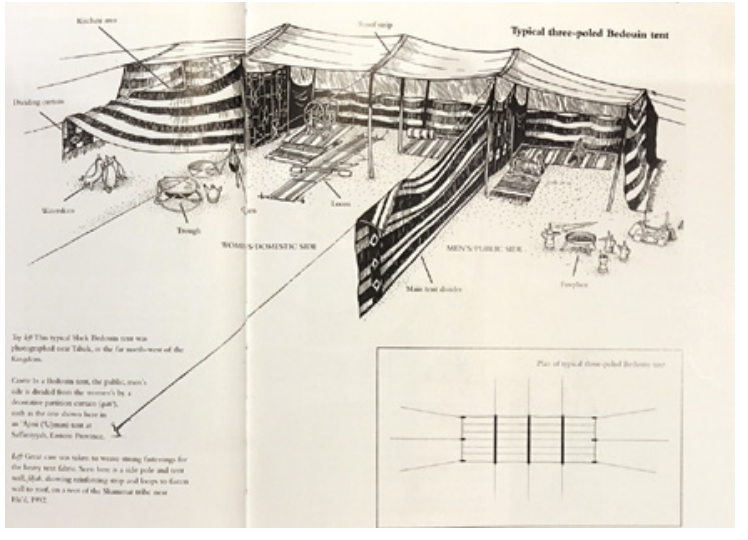

FIGURE 8.16 Typical three-poled Bedouin tent

black and white, with a little red-dyed wool for decoration. This wool comes from sheep and camels, whose wool is known for its softness and, when left undyed, for its beautiful natural colors. ${ }^{49}$

Figure 8.16 indicates the complex nature of the interior of a Bedouin tent. The inside area is divided into many parts, each of them with its specific use. It is important to note that a "well-to-do" Bedouin tent like the one shown in figure 8.16 indicates the higher status of the family living in it than that of a family living in the humbler,

For details, see Al-Sabah, Ibjad, 17. three-poled tent in figure 8.15. These images also show that different areas are used by men and by women. ${ }^{50}$ For example, the tent contains a space which is allocated to female weavers, like a studio where they perform their craft and practice their skills. ${ }^{51}$ Thus, in the Bedouin society, the tent is a not only a signifier of social relationships and family status but also of gender roles. It is, therefore, an extremely important space because here women make items that support their family or tribe.

While the function of the textile is to create and demarcate the Bedouin space, the way the space is constructed influences the way the nomads live and the way the family or the tribe is perceived by the outside world. The textile is, therefore, structuring the formation of a private and a public identity by delineating the space: the outside, nonpatterned textiles are public, while the inside, patterned textiles are private. ${ }^{52}$ We can infer,

See also Dickson, The Arab of the Desert, 66-67; and Canavan, "Applications of Textile Products," 541. Here, Canavan explains that dividers were parts of women's possessions, accompanying them into marriage, as well as "testimony of a tribe's wealth and prestige." Refah Al Raheel, interviewed by Rana Al-Ogayyel, Riyadh, 2017 .

52 While the outside of the traditional tents is black and without much pattern except for stripes, the inside of 
therefore, that the best way of accessing the private is to be able to "read," or decode, the textiles and to actually spin, dye, and weave patterns from wool. An important area of examination would be to establish if the different patterns in different areas inside the tent correspond to any delineated space. Because traditional tents have few, if any, windows, the woven patterns also serve as windows to the soul of the weaver, the tribe, and the external world, with all its geography and culture.

There is also a kind of versatility to the function of the textiles. As the tent dividers become old, they may be mended or turned into cushions, thus serving both sentimental and practical functions. The mending on the tent divider also creates a visual dialogue between the various generations of women in the family, assuming a life of its own and changing constantly due to the normal wear and tear and the relentless act of undoing, packing, carrying, and re-assembling required by the Bedouin life.

Women's activity in the home, in a noncommercial capacity, has often been regarded as essentially selfless: the Bedouin women did not take visible ownership of their creative work, which was seen as made for and by the community, as an expression of a plural identity. However, as a master of a craft, a female crafter has more power than a woman who does not practice one. Because the weaver was needed by the family and tribe to fill the home with objects made from alSadu textiles, she was in a position of power. Moreover, handmade artifacts suggest value, effort, and dedication and are more expensive than those serially-made by machines. They also represent unique human intentions, as they reflect the specific moment when the creation of the object took place in the life of a crafter, which is unique to that particular object and reflects the creator's memory and time. The weaver has the know-how and skill to provide the tribe with soft-furnished homes

the tent is decorated with patterns on tent dividers and cushions. and, in return, this gives her a higher status in the Bedouin society.

\section{Non-traditional Uses and Appropriations of Al-Sadu in Contemporary Art and Design}

In his seminal study, "The Work of Art in the Age of Mechanical Reproduction," Walter Benjamin notes: "The uniqueness of a work of art is inseparable from its being embedded in the fabric of tradition. This tradition itself is thoroughly alive and extremely changeable." ${ }^{33}$ The work of art and the craft object are similar in that they both reflect the uniqueness and the individuality of the artist. However, the craft object, more like a technical object, raises questions of function and use. Therefore, within the digital and media art, the relation between the hands of the artist and the work of art adds a new layer of complexity to the object.

While traditional weavers continue to practice their craft, the bold colors, symbolism, and narrative quality of al-Sadu have attracted a growing interest among many artists from Saudi Arabia, Kuwait, and the rest of the Gulf area. The use of traditional techniques in their practice has become a trend for the local artists. One such artist is

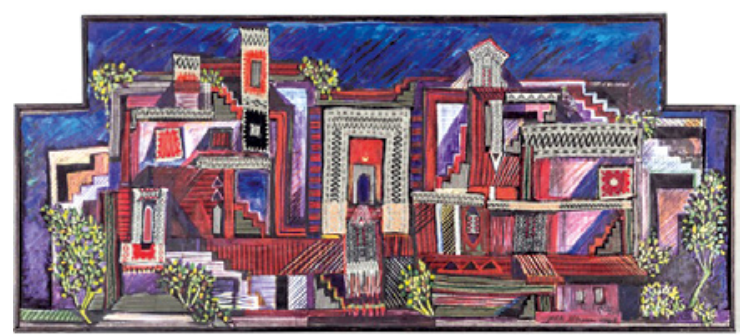

FIgURE 8.17 Nabila Al Bassam, "Bedouin Varieties," 1998-1999.

53 Walter Benjamin, "The Work of Art in the Age of Mechanical Reproduction," in Illuminations, ed. Hannah Arendt and trans. H. Zohn (New York: Schocken Books, 1969), 6. 


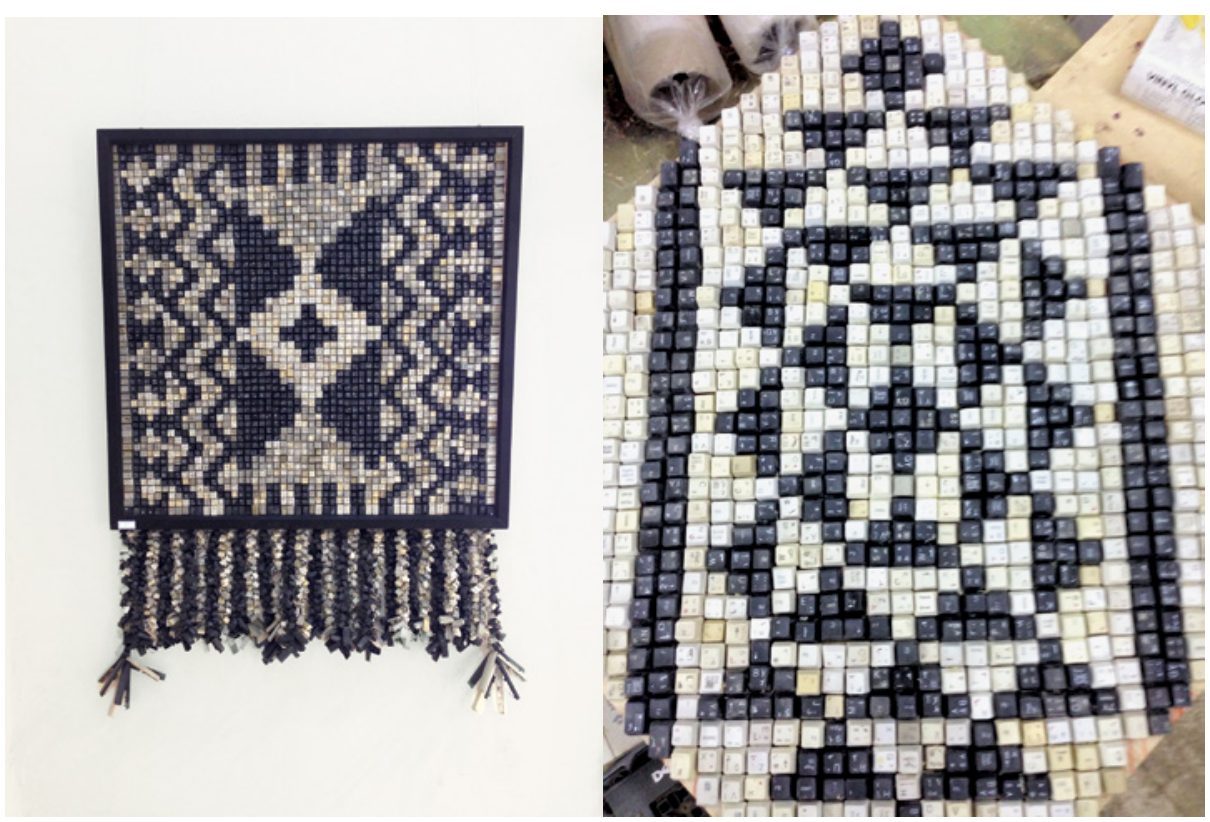

FIGURE 8.18A-B Al-Sadu weavings by Bader Al-Mansour, 2019.

Nabila Al Bassam, who has traveled to several cities in the Kingdom of Saudi Arabia to learn about local traditions and techniques in the production of al-Sadu weaving, textiles, and popular clothing. ${ }^{54}$ Choosing women as her inspiration, she imbued her work with vibrant colors aimed at asserting women's relationship with this ancestral art and celebrating its aesthetic beauty. In 1979, she started the Arab Heritage Gallery, where artists and craftsmen display their work in individual or group exhibitions. The first exhibition of the gallery fittingly displayed Bedouin weavings, along with other local forms of art and craft. Also, through her paintings, Al Bassam aims at highlighting women's relationship with the al-Sadu craft that they handed down over generations (fig. 8.17). If Al Bassam's interest in women is more didactic, focusing on their relation to heritage arts, another artist, Bader Al-Mansour, transforms

54 For more details about the artist, see "Nabila Al Bassam," Hafez Gallery, accessed May 25, 2018, https:// www.hafezgallery.com/copy-of-nabila-al-bassam-1, and the home page of the Arab Heritage Gallery, http:// www.arabheritage.com.sa/default.htm. non-textile materials into textile-like ones containing al-Sadu patterns and motifs (figs. 8.18a-b). As he explains, "as a Kuwaiti artist, I believe it is my duty to perpetuate my culture, and al-Sadu is an integral part of my identity." 55

Currently, there is a renewed interest in al-Sadu weaving both in the Arabian Gulf and internationally. Al Sadu Weaving Cooperative Society in Kuwait has the largest formal collection of al-Sa$d u$ weavings in the world, playing an important role in keeping the local culture alive and evolving. Al Sadu Society is located in a historic house formerly belonging to the Behbehani family in Kuwait. It is a museum-house for traditional $\mathrm{Ku}-$ waiti textiles, from nomadic weavings of the desert to new weaving styles, which is dedicated to preserving, documenting, and promoting this rich and diverse textile heritage. It celebrates the creativity of past generations and weaves together a cultural identity for both present and future

55 For details, see Chaitali B. Roy, “'Saduing' with Waste to Create Unique Art," The Arab Times, November 28, 2013, http://www.pressreader.com/kuwait/arab-times/2013 $1128 / 282518656290400$. 
generations by exhibiting historical weavings and holding weaving workshops, dyeing workshops, al-Sadu weaving exhibitions and competitions, and textiles fairs. It also has a gift-shop where variations on al-Sadu weaving or al-Sadu-inspired products are sold. Following many years of collaboration between contemporary artists and alSadu weavers, Al Sadu Weaving Cooperative Society held a multi-artist event in 2016, the "Sadu Art and Design Initiative” (SADI). This was a contemporary art exhibition of eight artists-in-residence who met over a period of a few months and created artwork inspired by al-Sadu. The group met weekly, had workshops on natural dyes, invited craftspersons and lecturers, and hosted an exhibition at Al Sadu Society in June 2016.56 The initiative was repeated in 2018, 2019, and $2020^{57}$ "Weaving Stories" was another exhibition curated by Sheikha Altaf Al-Sabah and supported by Leslie Robertson and Shelby Allaho. First exhibited at the Al-Shaheed Park in Kuwait City in November 2016 and later re-exhibited in many other locations in Kuwait, it brought together dozens of pieces by textile artists working across various textiles mediums and inspired by various themes related to Kuwait.

Another contemporary initiative inspired by alSadu is Zeri Crafts, a company created by Laila AlHamad, a Kuwaiti woman who used to work for the World Bank and who developed a sustainable, and ethical company based on project models she

$56 \quad$ Altaf Al-Sabah and Ceyda Oskay, SADI: Sadu Art and Design Initiative Exhibition Catalogue (Kuwait: Al Sadu Society and the National Council for Arts and Letters, 2016).

57 The artists who participated in SADI 2016 were Aziz AlHumaidhi, Amani AlThuwaini, Rua Al-Shaheen, Mona Al-Qanai, Muneera Al-Sharhan, Judy-Ann Moule, Adel Ashkanani, Manal AlDowayan, and Ceyda Oskay, who was also the curator of the project. The artists who participated in SADI 2019 were Mishari Al-Najjar, Munirah Al-Shami, Abdullah Al-Saleh, Jawad Al-Tabtabai, and Fadha Al-Omar. The artists who participated in SADI 2020 were Ahmad Jamal, Husain Al-Banay, Maha AlAsakar, Salem Al-Salem, and Sultan Samhan.

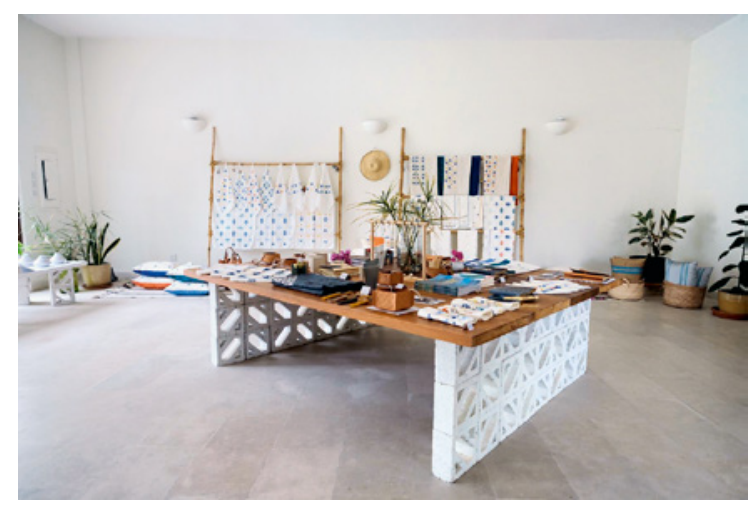

FIGURE 8.19 Zeri Crafts Showroom, Kuwait, 2019.

managed in Asia. In recent years, she held al-Sadu motif competitions to discover contemporary designs for her products. The brand includes al-Saduinspired designer products for the home, such as pillows, bedsheets, table cloths, and mubkhar (incense burner), as well as notebooks and bags for personal use (fig. 8.19). As Al-Hamad explains, "we create pieces that aspire to illuminate the beauty of our heritage and try, through design, to evoke concepts that were once intrinsic to this heritage, such as simplicity, modularity, functionality and understated aesthetic."58 Other Kuwaiti designers, such as Abdullah Al-Awadhi, Muneera Al-Sharhan, Fareed Abdal, and Reem Al-Shammari, have drawn inspiration from al-Sadu for their carpet, jewelry, and fashion designs, respectively.

\section{Conclusion}

Al-Sadu weaving plays an important role in the material culture of the Arabian Gulf. Al-Sadu iconography contains elements that are repeated over and over by different weavers who may give them different interpretations. Because al-Sadu displays an abstract, symbolic language whose meanings have been transmitted orally, it is a

$5^{8}$ Vittoria Volgare, "Meet the Kuwaiti Woman Reinventing Kuwaiti Traditions and Crafts," Muftah, May 1, 2018, https://muftah.org/meet-the-kuwaiti-woman-reinventing-gulf-traditions-and-crafts/\#.XESl8CgodDU. 
powerful form of expression for the women artists who practice it. As we have tried to suggest here, al-Sadu allows for a revaluation of women's status in the Arabian Peninsula and indicates that the women weavers used to play a central role in the tribe. In other words, we challenge here one of the many stereotypes about Arab societies perpetuated by Western cultures.

Al-Sadu also embodies the idea of home as a portable environment that is capable of adapting and mutating in relation to different landscapes and social contexts. The concept of home as an object, as well as a space, is very topical nowadays when computers and phones, these passe-partouts of contemporaneity, simultaneously represent an object/tool and an environment/home. Not coincidentally, digital artists traveling around the world have been called "digital Bedouins." Thus, while the lifestyle and the traditions of the Bedouin society are seen as archaic, some aspects of their modus vivendi can be considered as being ahead of time.

As noted above, the Bedouin tribes used to indicate their identity through an al-Sadu symbol called wasm, which was also used to mark animals. This was an identity marker more powerful than the space they belonged to. This trans-local use of a symbol to indicate a group united by an idea, a brand, or a kinship is common in our contemporary world, where identity is not necessarily related to belonging to a particular place. Similarly, although the Bedouin tribes move from one place to another, their identity can still be recognized even if they travel to a territory that does not belong to them. While abstraction is a distinctive form of postmodern communication, as seen, for example, in contemporary graphic design and advertising, it has been used by the Bedouin weavers for millennia. This form of visual language - which we believe to be the easiest way to communicate with other cultures - has become, once again, a fundamental medium of communication today given its unique power to be universally understood.

Each nation has its own treasures within its material culture. Today, as the world becomes closer and more similar due to globalization, it is the right time for artists and designers to take their local material culture to new places. As this chapter suggests, al-Sadu is a fertile medium for artistic exploration because of the unique relationship between its practical functions and its cultural associations. 